\title{
Management of structural and mechanical properties of moulding compound using mineral additives
}

\author{
Sergey Shakhov ${ }^{1, *}$, and Nikita Nikolaev ${ }^{1}$ \\ ${ }^{1}$ Siberian Transport University, Dusi Kovalchuk st., 191, 630049, Novosibirsk, Russia
}

\begin{abstract}
The purpose of work: the choice of the rational composition of the batch mixture, which improves the molding properties of the silt loams in the production of wall ceramics by the method of plastic molding. In the course of the study, the fraction-size distribution and morphological features of the fractions were analyzed on a photometric sedimentometer FSX-6K and by optical microscopy. Determination of the plastic strength of elasto-visco-plastic systems was carried out by Rehbinder's conical plastometer. The values of fast and slow elastic and plastic deformations were determined on an installation operating on the principle of a parallelshifting plate. For molding compounds with various corrective mineral additives, optimum values of molding moisture in which the compound is not adversely affected by shortage and excess moisture have been experimentally established; moduli of fast and slow elastic deformation and other structural and mechanical characteristics are determined. The percent values of the reduced deformations were obtained on the basis of rheological curves of disperse systems in the axes "deformation - shear time". It is established that the additions of components of different genesis and with different fraction morphology affect the deformation behavior of the molding compounds.
\end{abstract}

\section{Introduction}

In modern conditions, the development of production of wall ceramics is associated with a comprehensive analysis of the potential of local raw materials. Considering that in conditions of a lack of quality clays, the use of low-plastic silt loams as a main component of the batch mixture is becoming widespread, modern production of wall ceramic materials usually needs correction of clay raw materials.

Theoretical propositions of physical and chemical mechanics, developed by the efforts of Rebinder P.A., Kruglitsky N.H., Uriev N.B. and other scientists, admit the possibility of effective control of the rheology of dispersed systems not only due to mechanical effects and the use of surfactants but also by selecting corrective mineral additives of various origins [1-5]. In the literature, options are described for improving the properties of ceramic materials as a result of structure modification when introducing both highly dispersed and

\footnotetext{
*Corresponding author: sashakhov@mail.ru
} 
nanodispersed natural additives (wollastonite, diopside, etc.) [6-9] and man-made additives (ash, slag, silica and hydro alumina sol, etc.) [10-16].

In addition, up to the present time, a scientifically grounded approach to predict the effectiveness of the influence of certain additives on the rheology of highly concentrated alumina silica systems has not developed among specialists, and as a result, in practice, their choice is reduced to empirical selection. Taking into account the tendency to use multicomponent additives to improve the properties of ceramics, the task of selecting the rational composition of the batch mixture, which provides the rheological properties required for plastic molding, is even more complicated. One of the reasons for such a state is, in particular, a little knowledge of the effect of mineral fractions with different morphologies on the rheological behavior of the molding compounds.

During the molding process, the ceramic compound is exposed to mechanical actions of various kinds. The deformation behavior of such compounds during plastic molding can vary depending on the formed coagulation structure. It was shown in $[1,2,17]$ that the degree of development of such a structure is determined by the ability of the molding compound to plastic and elastic deformations. In addition, sufficiently complete information can also be obtained from rheological curves expressing the dependence of the degree of structural failure on the shear stress [2,18-20]. The basic structural and mechanical characteristics can be used as criteria for assessing the molding properties of clay raw materials. They can also be used to determine the static correlation between these characteristics and the basic natural properties of clays.

With this in mind, it is of scientific and practical interest to assess the structural and mechanical properties of molding compounds made of silt loams modified by mineral additives of different genesis and morphology.

The purpose of work: the choice of rational composition of the batch mixture, which improves the molding properties of the silt loams in the production of wall ceramics by the method of plastic molding.

\section{Materials and Methods}

During the study, loam of the Kamenskoye deposit of the Novosibirsk region was used as a clay raw material. Analysis of the granulometric composition showed (Fig. 1 a, b) that loams are silt ones and contain less than $20 \mathrm{wt}$ \% of clay fractions.

The wollastonite of the Sinyukhinskoye deposit, the granulated blast furnace slag of the West Siberian Combine, river sand (fraction size modulus is 0.7-1.0), and silica obtained using the technology used in [21] were used as modifying additives.

The features of natural wollastonite are elongated needle crystals. It is this structure of wollastonite rock fractions, according to a number of researchers [22,23], which determines the possibility of its use as a reinforcing agent for the production of ceramic materials with increased strength. Before use, wollastonite was mechanically activated in a ball mill to $\mathrm{S}=$ $6500 \mathrm{~cm} 2 / \mathrm{g}$.

Analysis of the macrostructure and phase composition of granulated blast furnace slag showed that its fractions are naturally permeated by micro- and macropores. The content of the glass rim in them is $65-97 \%$. The crystallized part of the slag (no more than $5 \ldots 10 \%$ ) is mainly represented by the pseudowollastonite $\alpha-\mathrm{CaO} \mathrm{SiO} 2(\mathrm{~d} / \mathrm{n}, \mathrm{A}-4.162 ; 2.921)$ and the melilite microlites $\mathrm{Ca} 2(\mathrm{Al}, \mathrm{Mg})[(\mathrm{Si}, \mathrm{Al}) 2 \mathrm{O} 7]$ with $(\mathrm{d} / \mathrm{n}, \mathrm{A}-3.105,2.876,2.738,2.522)$. For use as a slag additive, powders with a specific surface area of $4500 \mathrm{~cm} 2 / \mathrm{g}$ were prepared.

The silica sols are lyophilic colloidal systems with nanoscale fractions. The core surface of such a fraction consisting of silicon dioxide $(\mathrm{SiO} 2)$ is covered with silanol groups $\mathrm{Si}$ $\mathrm{OH}$, the dissociation of which causes the emergence of a double electric layer and a negative charge of the sol fractions. 
The granulometric composition and morphological features of the fractions were analyzed on a photometric sedimentometer FSX-6K and by optical microscopy (Fig. 1).

a)
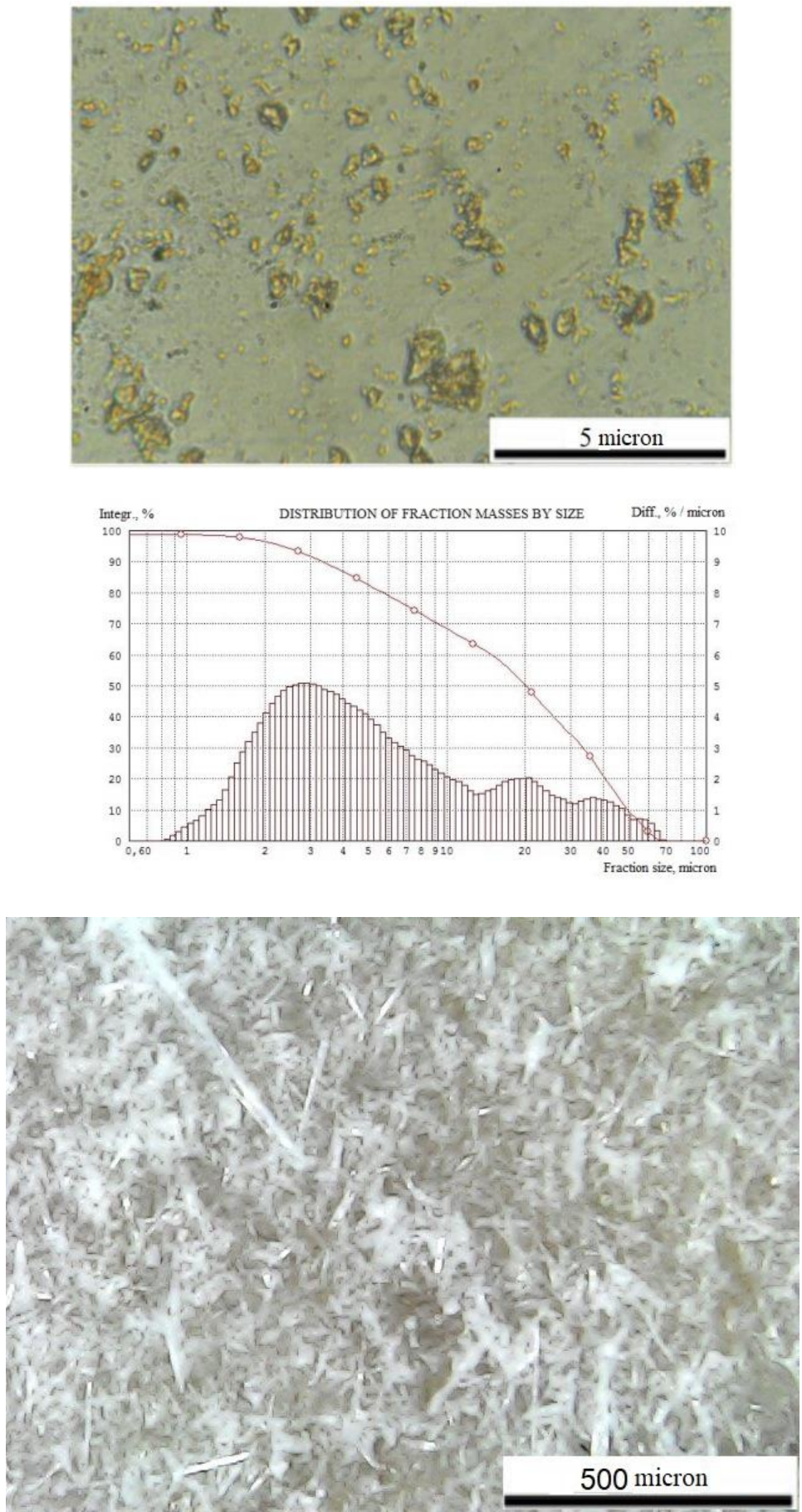


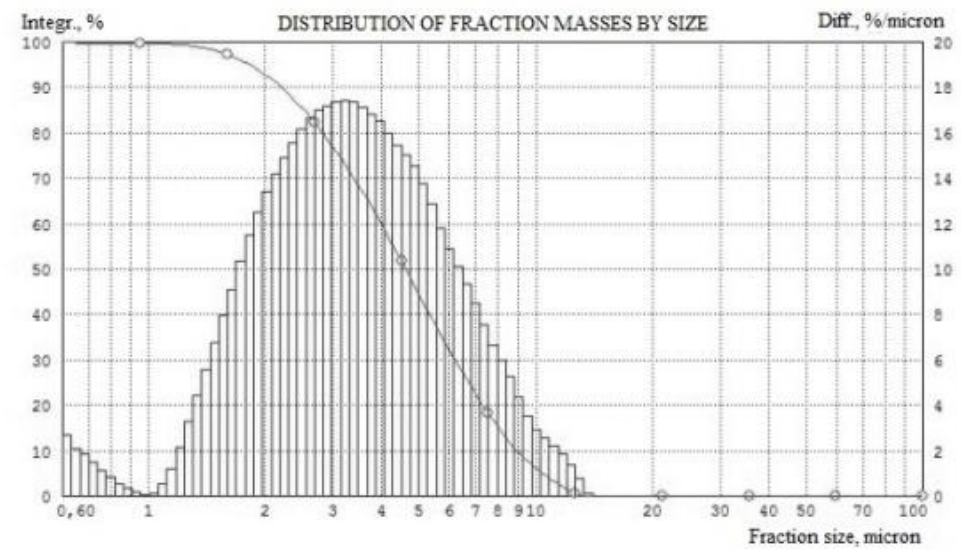

b)
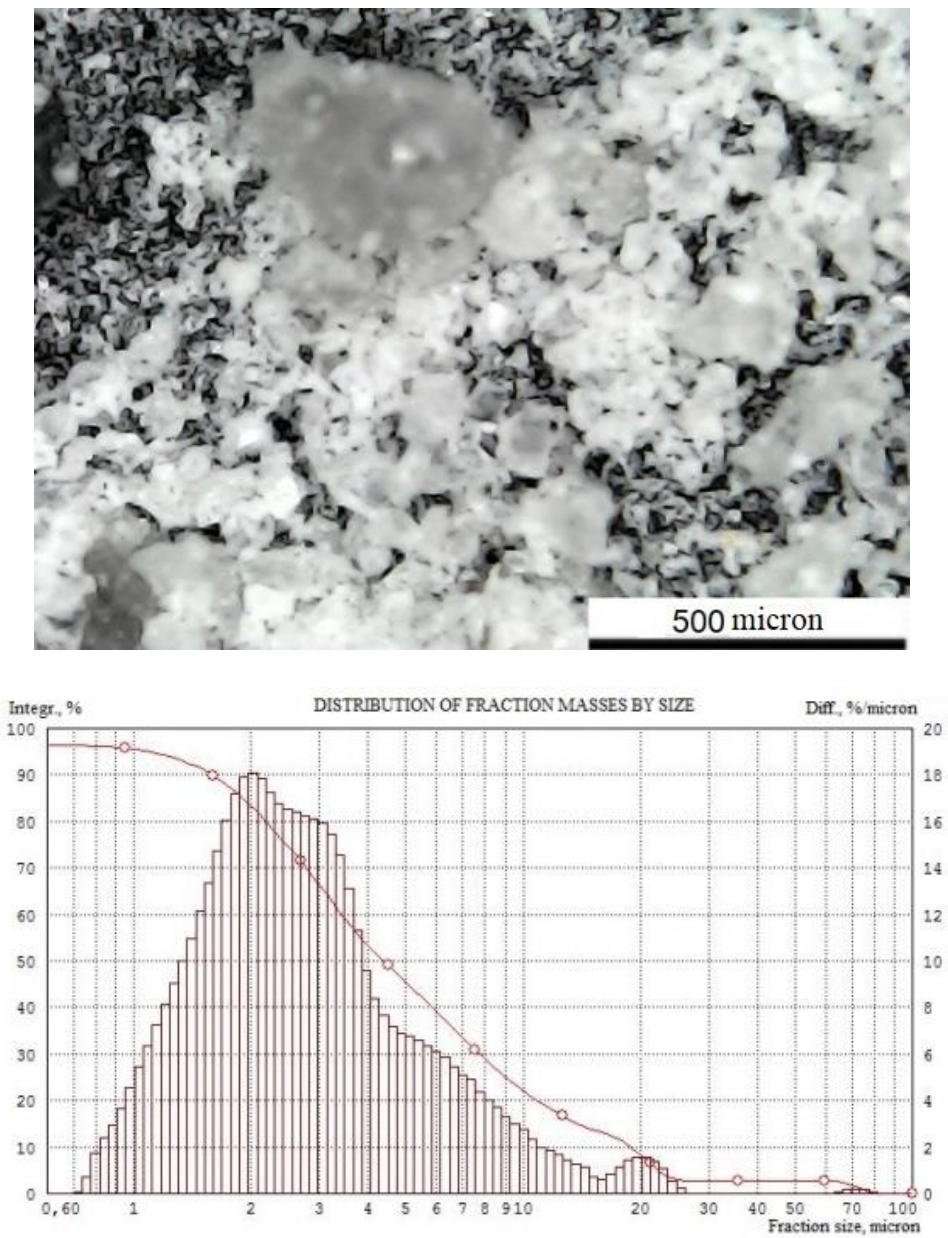
c)

d)
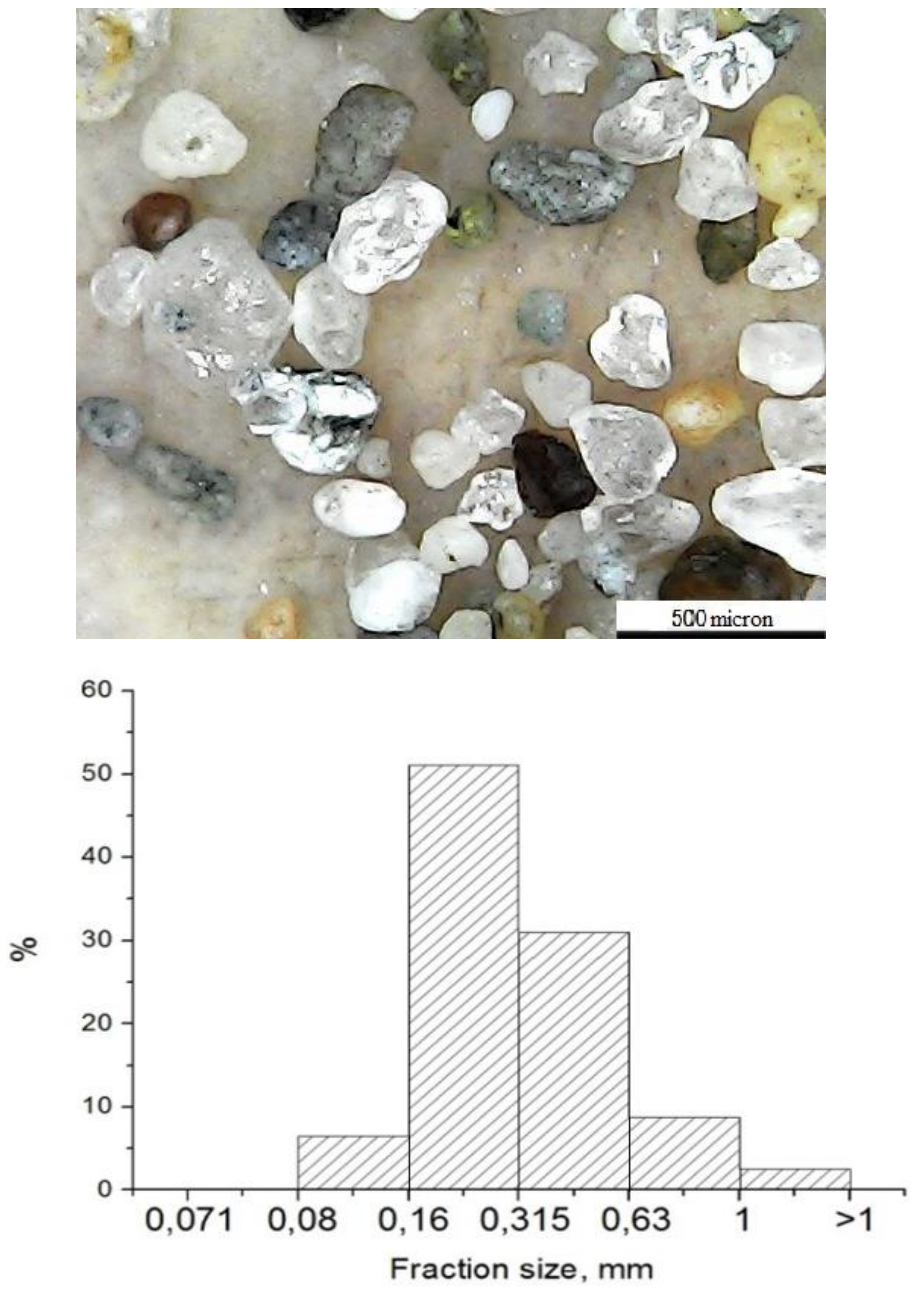

Fig. 1. Granulometric composition and micrographs of fractions: a - loam; b - wollastonite; $\mathrm{c}$ - blast furnace slag; $g$ - sand.

The effect of additives on the structural and mechanical characteristics of coagulation structures was assessed using methods of physical and chemical mechanics. Determination of the plastic strength of elasto-plastic-viscous systems was carried out by Rehbinder's conical plastometer. The method does not contain empirical constants and makes it possible to make measurements at small velocity gradients [24]. The values of fast and slow elastic and plastic deformation were determined on an installation operating on the principle of a parallel-shifting plate (D.M. Tolstoy's instrument).

The results of measurements on this installation make it possible to obtain a family of rheological curves in the system "deformation $(\varepsilon)$ - shear time $(\tau)$ " [25]. On the basis of these curves, the structural and mechanical characteristics of ceramic compounds with a nearly undistracted structure were determined graphically. From the obtained series of curves for each sample, moduli of fast elastic $E_{1}$, slow elastic deformations $E_{2}$, elasticity $\lambda$, and other structural and mechanical characteristics were calculated.

One of the criteria for the optimum suitability of molding compounds for plastic molding is the ratio of fast and slow elastic and plastic deformations [26, 27]. Taking into account the recommendations of the authors of papers $[1,3,27]$ and being guided by the 
structural and mechanical characteristics of the compounds used in the production plants for wall ceramics, the following was accepted as a criterion for the optimum suitability of the molding compounds for plastic molding:

$$
\varepsilon_{\mathrm{rev}}=33,3 \%+-30 \% ; \varepsilon_{\mathrm{pl}}=33,3 \%+-30 \% ; \varepsilon_{\mathrm{rev}}+\varepsilon_{\mathrm{el}}+\varepsilon_{\mathrm{pl}}=100 \%
$$

where $\varepsilon_{\mathrm{rev}} ; \varepsilon_{\mathrm{el}} ; \varepsilon_{\mathrm{pl}}$ - the proportion of reversible, elastic, and plastic deformations, respectively, determined according to the procedure [25].

To study the joint effect of the type, concentration, and ratio of components on the structural and mechanical properties of the molding compound, mathematical design of the experiment was used. The construction of the experimental matrix and the statistical processing of the data obtained were carried out in accordance with the methodology [28].

\section{Results and Discussions}

Moldability of compounds based on clay raw materials can be characterized by the value of the mechanical strength of the structure, which is determined by the critical shear stress at low strain rates [25]. The latter is commonly assessed at normal molding moisture, which characterizes the complete development of hydrate shells in a dispersed system and is determined by the point of intersection of two straight sections of the plastic strength moisture relationship.

The results of the determination of the plastic strength of the molding compounds studied by Rehbinder's conical plastometer are shown in Fig. 2. For all compositions, the character of the curves of the dependence of the plastic strength on moisture does not change and is expressed by two rectilinear sections that characterize respectively the region of successive development of adsorption films and hydrate shells, and the region of excessive (free) water [24].

The decrease in plastic strength with increasing moisture is associated with an increase in the distance between the fractions of the solid phase due to the development of hydrate shells on them and the appearance of kinetically free water in the system.

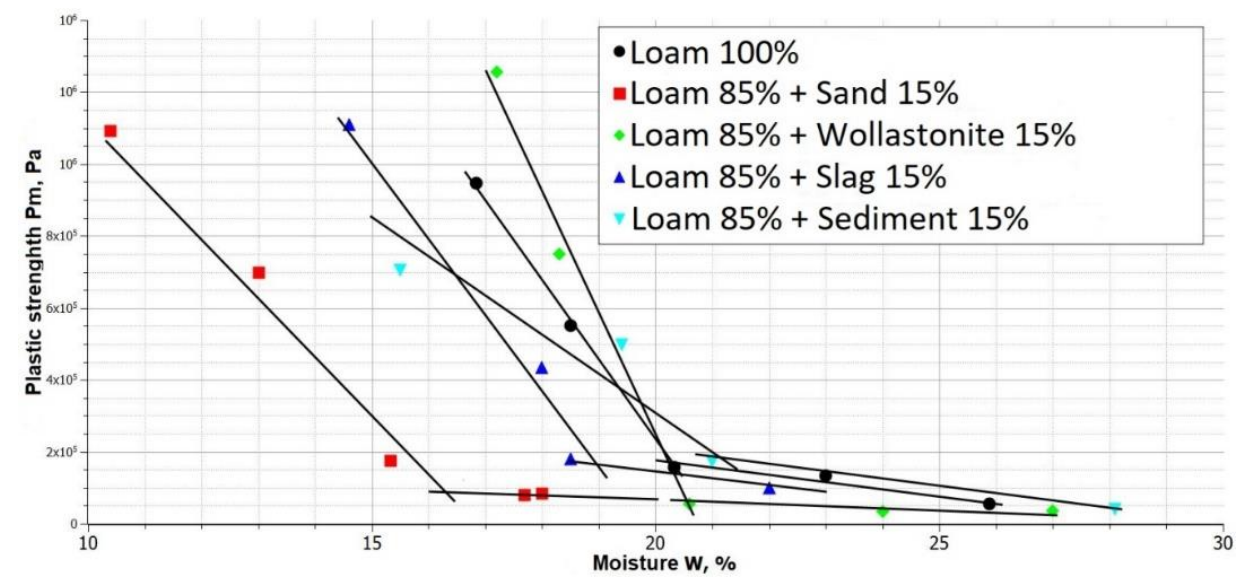

Fig. 2. Dependences of the plastic strength of molding compounds with additives of different nature $\left(\mathrm{P}_{\mathrm{m}}, \mathrm{Pa}\right)$ on its moisture content $(\mathrm{W}, \%)$ and sediment.

Analysis of the dependences shown in Fig. 2 shows that the effect of additives on the value of normal moisture (the point of intersection of rectilinear sections) is due to the size of fractions: the larger they are and the larger the content of the additive in the batch mixture, the lower the value of normal moisture. 


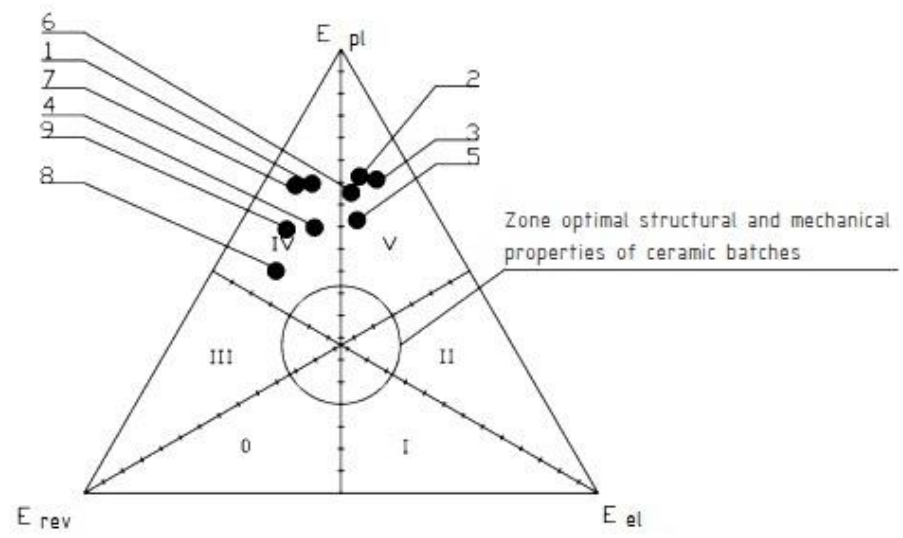

Fig. 3. Triple diagram of the reduced deformations for the batch composition.

Table 1. Triple diagram of the reduced deformations for the batch composition.

\begin{tabular}{|c|c|c|c|c|c|c|c|c|c|}
\hline \multirow[t]{3}{*}{ No } & \multicolumn{5}{|c|}{ Batch composition, $\%$} & \multirow{2}{*}{\multicolumn{4}{|c|}{$\begin{array}{l}\text { Structural and mechanical } \\
\text { characteristics }\end{array}$}} \\
\hline & \multirow[b]{2}{*}{ loam } & \multicolumn{4}{|c|}{ Additives } & & & & \\
\hline & & silica sol & wollastonite & slag & sand & $\varepsilon_{\text {rev }}$ & $\varepsilon_{\mathrm{el}}$ & $\varepsilon_{\mathrm{pl}}$ & $\tau$ \\
\hline 1 & 100 & - & - & - & - & 23 & 9 & 68 & 283 \\
\hline 2 & 100 & 20 & - & - & - & 12,7 & 15,6 & 71,7 & 93,4 \\
\hline 3 & 100 & 40 & - & - & - & 10,9 & 19,6 & 69,5 & 131 \\
\hline 4 & 85 & - & 15 & - & - & 27,8 & 13,9 & 58,3 & 464 \\
\hline 5 & 70 & - & 30 & - & - & 15,7 & 20,2 & 64,1 & 178 \\
\hline 6 & 85 & - & - & 15 & - & 15,1 & 17,6 & 67,3 & 216 \\
\hline 7 & 70 & - & - & 30 & - & 24,5 & 7,2 & 68,3 & 349 \\
\hline 8 & 85 & - & - & - & 15 & 37,7 & 11,5 & 50,8 & 728 \\
\hline 9 & 70 & - & - & - & 30 & 31,3 & 11,5 & 57,2 & 420 \\
\hline
\end{tabular}

To assess the rheological properties of the molding compounds with additives of different composition, their structural, mechanical, and deformation characteristics were determined. As can be seen from the characteristics given in Fig. 3, the loam refers to the IV structural and mechanical type. A distinctive feature of compounds of this type is a significant development of plastic deformations, small values of fast and slow elastic deformations and a period of true relaxation. Compounds of this type are very plastic, easily deformed, and exhibit a tendency to plastic destruction [29].

Addition of silica sol, as well as wollastonite, to loam leads to a decrease in the relaxation period in comparison with the initial clay system and promotes the development of slow elastic deformations. At the same time, blast furnace slag, as well as quartz sand traditionally used in practice as a thinning additive, contributes to the growth of rapid and slowing down of slow elastic and plastic deformations, which may be related to a decrease in the thinning function of these components. In this case, since such compounds (IV-th and V-th structural and mechanical types) do not require significant forces for deformation, sufficient internal stress compensation takes place, which increases the probability of continuity of molding without defects $[27,30]$. One of the criteria for the suitability of molding compounds for plastic molding is the ratio of various types of deformation (rapid, slow elastic and plastic deformations) [25-27]. However, it should be noted that there is no consensus on the question of which ratio of deformations is optimal until now. In works $[29,30]$, preference is given to the molding compounds of the I-st and especially the II-nd structural and mechanical type, i.e. the compounds in which slow elastic deformations 
predominate. The authors of $[27,31]$ recommend to use molding compounds with a uniform development of all types of deformations for plastic molding. At the same time, they do not identify any structural and mechanical types as optimal ones. Focusing on the structural and mechanical characteristics of the molding compounds used in the plants for the production of wall ceramics in the West Siberian region, in our opinion, it is the latter view that is most preferable. Having analyzed, taking into account the accepted assumption, the nature of the effect of additives with different morphology of fractions on the structural and mechanical characteristics of loam-based molding compounds, it can be concluded that the introduction of additives makes it possible to change the relationship between different types of deformations. However, regardless of the nature and morphology of the fractions, none of the studied additives provides a uniform development of all types of deformations in the molding compound. Considering that at present, one of the promising directions for improving the technology of building ceramics is the use of batch mixtures of composite technological additives consisting of components of different functional purpose for improving the molding properties [32], it seems expedient to further assess the effectiveness of controlling the rheological behavior of molding compounds using similar additives. Experiments to assess the joint effect of the type, concentration, and ratio of components on the structural and mechanical properties of the molding compound were carried out for systems: "loam - silica - wollastonite", "loam - silica - slag", "loam - silica - sand". In accordance with the second-order orthogonal plan, the factorial experiments $3^{2}$, as the investigated factors were adopted:

$\mathrm{x}_{1}$ - content of the coarse-dispersed leaner (wollastonite, slag, sand), $\%$;

$\mathrm{x}_{2}$ - content of sol, $\%$.

As a response function, we considered:

$\mathrm{y}_{1}$ - percentage of reduced plastic deformations, $\%$;

$\mathrm{y}_{2}$ - percentage of reduced slow elastic deformations, $\%$.

Based on the experimental data, regression equations were obtained and the response surfaces were constructed (Fig. 7, 8) showing the effect of the amount and the relationship between the additive components on the rheological characteristics of the molding compound.

$$
\begin{aligned}
& Y_{1 \text { slag }}=57,8-2,9 * x_{1}-0,64 * x_{2}-2,9 * x_{1} * x_{2}+1,19 *\left(x_{1}^{2}-0.67\right)+14 \\
& *\left(x_{2}^{2}-0.67\right)
\end{aligned}
$$

$F_{\mathrm{r}}=3,05<F_{\text {cr }}=3,6-$ model is valid.

$$
\begin{aligned}
& Y_{1 \mathrm{wol}}=53,5-7,59 * x_{1}-4,86 * x_{1} * x_{2}-5,91 *\left(x_{1}^{2}-0,67\right)-4,36 \\
& *\left(x_{2}^{2}-0,67\right)
\end{aligned}
$$

$F_{\mathrm{r}}=3,25<F_{\text {cr }}=3,6-$ model is valid.

$$
Y_{1 \text { sand }}=64,4-3,5 * x_{1}+6,00 * x_{1} * x_{2}
$$

$F_{\mathrm{r}}=3,54<F_{\mathrm{cr}}=3,6-$ model is valid.

$$
Y_{2 \text { slag }}=17,75-6,22 * x_{1}-2,05 * x_{2}+4,88 *\left(x_{1}^{2}-0.67\right)-4,61 *\left(x_{2}^{2}-0.67\right)
$$

$F_{\mathrm{r}}=3,31<F_{\text {cr }}=3,6-$ model is valid.

$$
Y_{2 \mathrm{wol}}=21,38+2,00 * x_{2}+4,42 * x_{1} * x_{2}
$$

$F_{\mathrm{r}}=3,2<F_{\mathrm{cr}}=3,6-$ model is valid.

$$
Y_{2 \text { sand }}=19,03+4,61 * x_{1}-2,05 * x_{2}+4,21 *\left(x_{2}^{2}-0.67\right)-3,83 * x_{1} * x_{2}
$$

$F_{\mathrm{r}}=3,55<F_{\text {cr }}=3,6-$ model is valid. 
a)

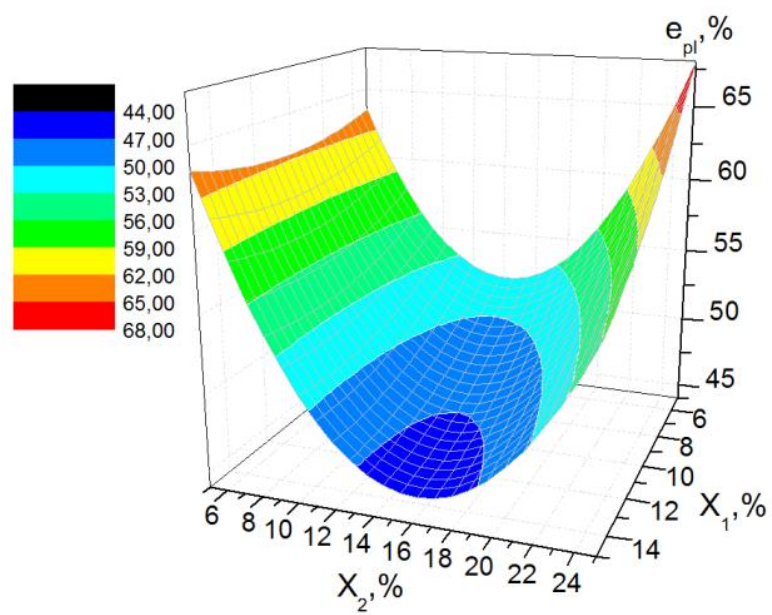

b)

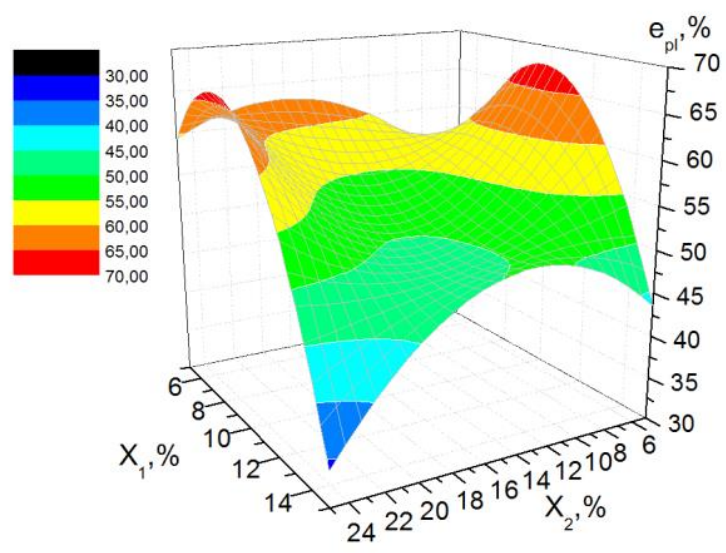

c)

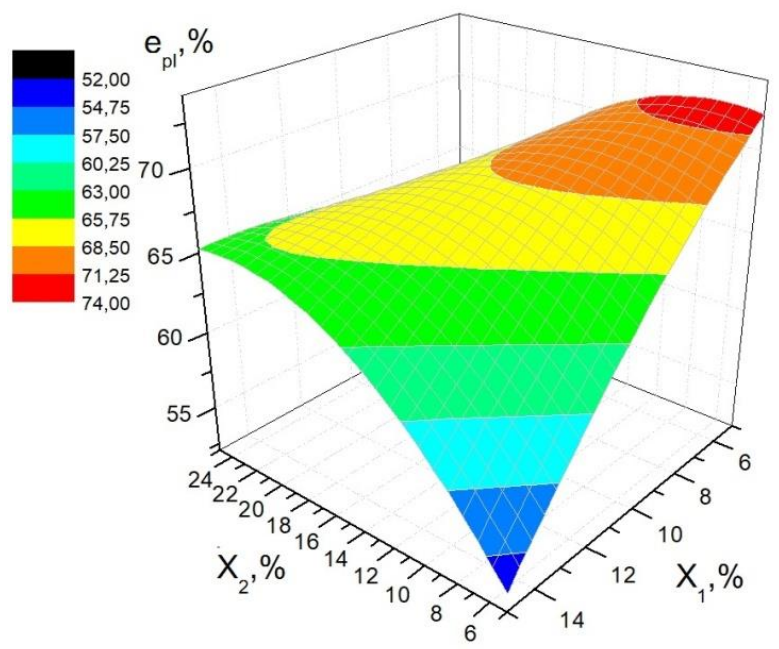

Fig. 4. The influence of the ratio of components of the complex additive on the value of the reduced plastic deformations of the systems: a - "loam - sol - GBFS"; b - "loam - sol - wollastonite"; c "loam - sol - sand". 
a)
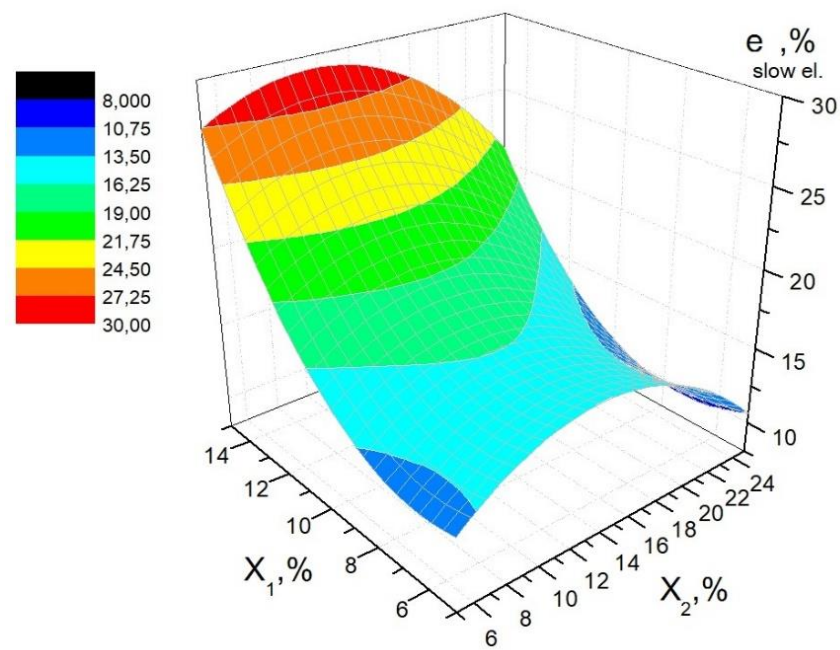

b)

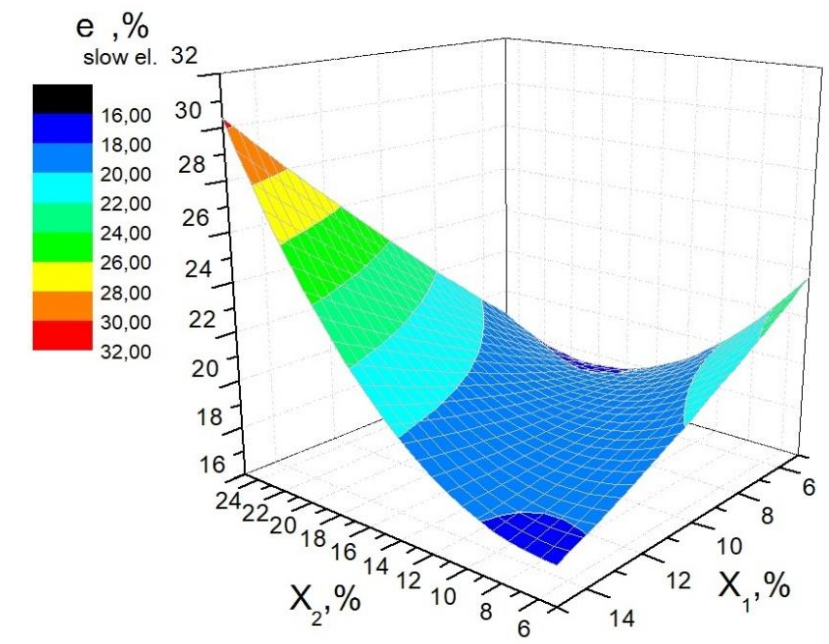

c)

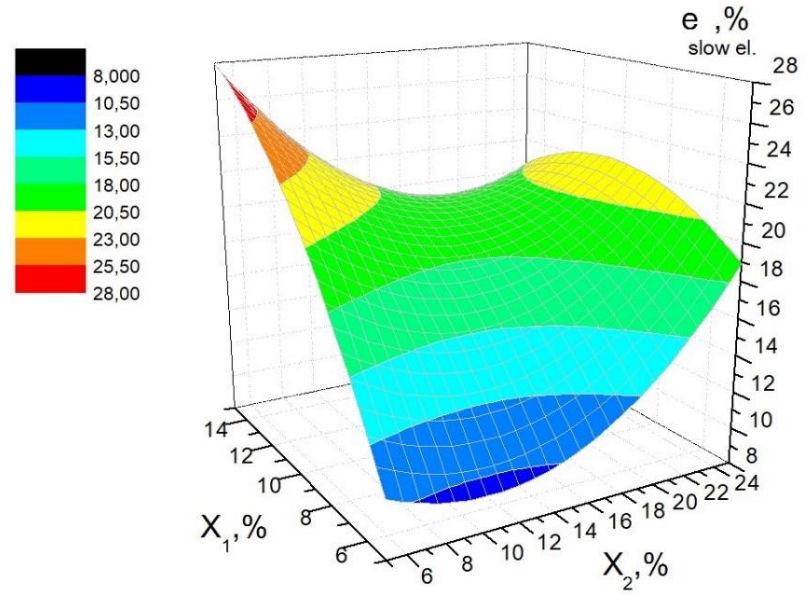

Fig. 5. The influence of the ratio of components of the complex additive on the value of the reduced elastic deformations of the systems: a - "loam - sol - GBFS"; b - "loam - sol - wollastonite"; c "loam - sol - sand". 
Analysis of response surfaces (Figures 4 and 5) constructed using regression equations (2-7) indicates that the combined introduction of a sediment with granulated blast furnace slag or with wollastonite results in a more significant redistribution of deformations from plastic to slow elastic deformations than when using these additives separately. This allows obtaining molding compounds with deformation values located in the target zone. Such changes in the deformation behavior of the molding compounds are apparently related to the intensification of the coagulation structure formation process due to the adsorption of colloidal sol fractions on the surface of the thinning components, which facilitates the lyophilisation of their surface of coarsely dispersed fractions, providing a link between them via molecular (van der Waals) and ionic forces through a layer of the dispersion medium.

The analysis of the obtained results made it possible to choose the batch mixture compositions (Table 3) ensuring the development of all types of deformations in the process of plastic molding in accordance with the chosen target criterion (1). At the same time, the normal moisture content of such compositions is about $19-21 \%$, which is an acceptable value from the point of view of existing technological processes, since in the production, compounds with moisture content of $18-20 \%$ are used for plastic molding (Table 2).

Table 2. Structural and mechanical characteristics of batch mixtures of optimum composition.

\begin{tabular}{|l|c|c|c|}
\hline \multirow{2}{*}{$\begin{array}{l}\text { Structural and } \\
\text { mechanical } \\
\text { characteristics }\end{array}$} & $\begin{array}{c}\text { C5\% loam }+15 \% \text { sand }+ \\
15 \% \text { sol (to 100\% of } \\
\text { compound) }\end{array}$ & $\begin{array}{c}85 \% \text { loam }+15 \% \\
\text { GBFS+15\% sol (to } \\
100 \% \text { of compound) }\end{array}$ & $\begin{array}{c}\text { 85\% loam }+15 \% \\
\text { wollastonite+15\% sol } \\
\text { (to 100\% of } \\
\text { compound) }\end{array}$ \\
\hline $\begin{array}{l}\text { Optimum molding } \\
\text { moisture Wopt.m. } \%\end{array}$ & 18,5 & 19 & 21,3 \\
\hline Relaxation period $\theta$, sec & 320 & 938 & 1068 \\
\hline Elasticity $\lambda$ & 0,583 & 0,44 & 0,45 \\
\hline $\begin{array}{l}\text { Fast elastic deformation } \\
\text { erev, } \%\end{array}$ & 19 & 28 & 31 \\
\hline $\begin{array}{l}\text { Slow elastic } \\
\text { deformation el } \%\end{array}$ & 26 & 31 & 31 \\
\hline $\begin{array}{l}\text { Plastic deformation } \mathrm{e}_{\mathrm{pl}}, \\
\%\end{array}$ & 55 & 41 & 38 \\
\hline $\begin{array}{l}\text { Structural and } \\
\text { mechanical type }\end{array}$ & $\underline{\mathbf{V}}$ & $\underline{\mathbf{V}}$ & $\underline{\mathbf{V}}$ \\
\hline
\end{tabular}

\section{Conclusions}

1. Experimental studies of rheological behavior of molding compounds made of low-grade clay raw materials and modifying additives of different genesis and morphology have been carried out. It has been established that the joint introduction of silica sol in the form of filtrate of the water treatment sediment and highly dispersed fractions of the thinning agent (sand, wollastonite, slag) affects the deformation behavior of the molding compounds.

2. Optimum values of molding moisture at which the compound is not subjected to the negative influence of lack and excess moisture are experimentally determined. For the studied compositions, the molding moisture should be $18-21 \%$. 
3. The joint introduction of a composite additive made of silica sol and finely dispersed fractions of the thinning agent (wollastonite, granulated blast furnace slag) into the composition of the batch mixture made of loam makes it possible to control the structural and mechanical characteristics of the molding compounds by changing the ratio between the above-mentioned components.

4. Based on the results of experimental studies, the compositions of batch mixture are chosen to ensure that all types of deformation correspond to the chosen target criterion.

5. The approach to controlling the structural and mechanical characteristics of lowplastic ceramic compounds by using an additive representing a composition of components of different genesis and with different fraction morphology can be used not only in the production of bricks but also in the production of other products, for example, ceramic blocks of complex geometric forms.

\section{References}

1. N.B. Uryev, Physical and chemical foundations of technology of disperse systems and materials (Chemistry, Moscow, 1988)

2. P.A. Rebinder, Selected Works. Surface phenomena in disperse systems. Physicoal and chemical mechanics (Nauka, Moscow, 1979)

3. N.N. Kruglitsky, Physical and chemical foundations for regulating the properties of dispersions of clay materials (Naukova Dumka, Kiev, 1968)

4. N. Ozkan, J. European Ceramic Society 19-16, 2883-2891 (1999)

5. D. Doraiswamy, Ceram. Mater. and Compon. Engines, 380-398 (1989)

6. S.A. Shakhov, T.L. Rudaya, Patent of the Russian Federation №2581588, IPC C04/B33/02, Batch mixture for the manufacture of ceramic, FSUE HPE SSTU

7. A.Yu. Stolboushkin, Building Materials 8, 13-17 (2014)

8. P. Ciullo, Paint and Coatings Industry 11, 50 (2009)

9. V.I. Vereshchagin, Glass and ceramics 11, 13-16 (2010)

10. L.P. Chernyak, V.I. Trubachev, B.C. Pyshnoy, Glass and ceramics 10, 17-19 (1981)

11. L.B. Svatovskaya, N.A. Babak, A.M. Slavina, L.L. Maslennikova, Patent of the Russian federation №2412131, IPC C09B 3/00, Batch mixture for the manufacture of ceramic bricks

12. V.S. Bakunov, S.V. Sudareva, L.M. Delitsyn, V.M. Korotky, N.E. Korobov, Patent of the Russian Federation №2638996, IPC C04B 33/135, Batch mixture for the production of clay sol brick

13. V.T. O’Brien, Langmuir 16(21), 7931-7938 (2000)

14. A.R. Jacob, J. Non-Newtonian Fluid Mech 206, 40-56 (2014)

15. I.A. Zhenzhurist, Izvestiya of the Kazan State Architectural and Construction University 1, 281-286 (2010)

16. S.A. Shakhov, Bulletin of the SSTU 1, $42-48$ (2015)

17. M.J. Armstrong, Journal of Rheology 60(3), 433-450 (2016)

18. S.C. Danforth, CIM Bull D2- 926, 88 (1989)

19. Yu.E. Pivinsky, Refractories 12, 11-19 (1995)

20. P.R. de Souza Mendes, R.L. Thompson, A A. Alicke, R.T. Leite, J. Rheol 58, 537-561 (2014)

21. S.A. Shakhov, Bulletin of the SSTU 1, $61-67$ (2018) 
22. G.K. Maslennikova, Glass and ceramics 4, 25-27 (1995)

23. T.V. Vakalova, Glass and ceramics 5, 23-26 (2003)

24. V.L. Balkevich, Yu.M. Mosin, M.N. Firsova, Glass and ceramics 4, $16-17$ (1980)

25. Workshop on the technology of ceramics and refractories (Stroiizdat, Moscow, 1972)

26. B.J. Briscoe, J. European Ceramic Society 17-14, 1675-1683 (1997)

27. A.P. Ilin, Physical and chemical mechanics in the technology of catalysts and sorbents: Monograph (Ivan. state. chem. technol. un-t. Ivanovo, 2004)

28. Methodology of experiment planning: guidelines for laboratory work (UISTU, Ulyanovsk, 2011)

29. Physical and chemical mechanics of dispersed minerals (Naukova Dumka, Kiev, 1968)

30. V.A. Dzisko, Basics of methods for the preparation of catalysts (Nauka, Novosibirsk, 1983)

31. A.N. Trofimov, A.P. Ilyin, Yu.G. Shirokov, Sib. chem. journ. 5, 150-155 (1991)

32. E.A. Kucherova, Journal of the Russian Universities. Construction 3, 24-31 (2016) 